\title{
Phytochemical Screening, Cytotoxic and Antioxidant Activity of Alternathera sessilis and Moringa oleifera
}

\author{
Ishwor Pathak ${ }^{1 *}$, Rabin Budhathoki ${ }^{1}$, Nisha Yadav ${ }^{1}$, Muna Niraula ${ }^{2}$, Surya Kant Kalauni * \\ ${ }^{1}$ Department of Chemistry, Amrit Campus, Tribhuvan University, Kathmandu, Nepal \\ ${ }^{2}$ Department of Forest and Soil Conservation, Babarmahal, Kathmandu, Nepal \\ ${ }^{3}$ Central Department of Chemistry, Tribhuvan University, Kathmandu, Nepal \\ "Email: pathakishwor14@gmail.com \& skkalauni@gmail.com
}

(Received: 19 April, 2020, Received in revised form: 2 August, 2020, Accepted:10 August, 2020, Available online)

\section{Highlights}

- Methanol and hexane extracts of Moringa oleifera and Alternanthera sessilis were prepared.

- Phytochemical screening, brine shrimp bioassay, and antioxidant activity test of each extract of both plants were performed.

- Alternanthera sessilis extracts showed high toxicity against brine shrimp larvae.

- Methanol extract of both plants showed the highest antioxidant activity.

\begin{abstract}
Methanol and hexane extracts of leaves of Moringa oleifera and aerial parts of Alternanthera sessilis were screened for the presence of different classes of phytoconstituents. Phytochemical screening revealed the presence of alkaloids, flavonoids, carbohydrates, terpenoids, polyphenols, glycosides, and coumarins in methanol extracts. Volatile oils, quinines, and phytosterols were absent in all extracts and saponins were present in all extracts. The biological activity of all the extracts was tested by performing brine shrimp bioassay. All the extracts except hexane extract of Moringa oleifera were found to be cytotoxic against brine shrimp nauplii. 1,1-diphenyl-2-picrylhydrazyl (DPPH) radical scavenging assay was used to evaluate the antioxidant activity of the extracts. Methanol extracts of Moringa oleifera showed the strongest antioxidant activity with an $I C_{50}$ value of $65.77 \mu \mathrm{g} / \mathrm{mL}$. Regarding the ascorbic acid (IC ${ }_{50}$ value $39.53 \mu \mathrm{g} / \mathrm{mL}$ ) as standard, methanol extracts of both plants showed high free radical scavenging activity than that of hexane extracts.
\end{abstract}

Keywords: Extract, phytochemicals, antioxidants, brine shrimp bioassay

\section{Introduction}

Plants possess a wide variety of secondary metabolites that are rich in antioxidant activities and other several therapeutic values (Harborne, 1998). Several bioactive molecules can be isolated from the plants and such molecules serve as a starting material for drug synthesis (Dhanani et al. 2017). Medicinal plants have been used by mankind for the treatment of various ailments for thousands of years (Siew et al. 2014).

Moringa oleifera, a member of moringaceae family is a native to Indian subcontinents, Africa, and Nepal (Bukar et al. 2010). Moringa trees are commonly known as "drumstick" and its Nepali name is sittalchini. It is a highly valued plant for

${ }^{*}$ Corresponding author 
nutritional food and medication. People use its leaves, flowers, roasted seeds, and fresh pods as vegetables, seeds as cooking and cosmetic oils and roots for spice (Anwar et al. 2006). It can also be used as a livestock feed. The chemical composition of the fiber present in it affects the digestive ability of animals (Moyo et al. 2011). Moringa seeds have shown analgesic, antipyretic, hepatoprotective and wound healing activities. Its leaves are natural energy booster as it contains more than 14 amino acids, carbohydrates, proteins, vitamin A, C and E, calcium, and magnesium that the human body requires (Kumbhare et al. 2012), (Shahriar, 2012). A variety of biological activities of different parts of the $M$. Oleifera have been reported to date and this plant can serve a potent antioxidant supply for both human beings and animals (Suphachai, 2014), (Arora \& Onsare, 2014), (Hossain et al.2014).

Alternanthera sessilis (L.), commonly known as "bhiringijhar" in Nepal, belongs to the family Amaranthaceae. It is an aquatic plant and commonly observed in marshy areas, wetlands, streams, reservoirs, and river banks (Hossain et al. 2014). Geographically, it is native to Asia, Australia, and different Islands. In Nepal and Indian subcontinents, people use this plant to treat gonorrhea, low sperm count, treatment of burning sensation, diarrhea, skin diseases, fever, cuts and wounds, liver, and spleen diseases (Rahman \& Gulshana, 2014), (Nayak et al. 2010). It contains bioactive phytoconstituents especially polyphenols, alkaloids, stigmasterol, campesterol, palmitates of sterol, etc. (Walter et al. 2014). Aerial parts of this plant are a good source of minerals, vitamins, pigments, and antioxidants. The therapeutic values of this plant are closely associated with the presence of these active constituents (Jalalpure et al. 2008), (Borah et al. 2011). Several previous studies reported that the $A$. sessilis found in other countries have high scavenging activities; however, any report of antioxidant activity of $A$. sessilis found in Nepal has not been reported to date (Balakrishnan et al. 2013), (Borah Iet al. I 2011), (Murugan et al. 2013). An attempt has been made in this study to compare phytochemicals, antioxidant and cytotoxic activities of $A$. sessilis and $M$. oleifera found in different habitats and geographical regions of Nepal.

\section{Materials and Methods}

\section{Plant materials}

Aerial parts of Alternanthera sessilis and matured leaves of Moringa oleifera were collected from Dang and Rautahat districts of Nepal respectively, in the December month of 2018. The plants were authenticated at the Department of Botany, Amrit Campus, Kathmandu, Nepal. The collected samples were cleaned, shade dried and powdered and stored in airtight bottles.

\section{Extraction}

The dried and powdered parts of Alternanthera sessilis and Moringa oleifera were extracted separately with two different solvents hexane and methanol by using soxhlet apparatus. Accurately weighed $50 \mathrm{~g}$ powdered samples of each plant were filled separately in each thimble and placed in the central assembly of the soxhlet apparatus. Accurately measured $300 \mathrm{~mL}$ solvents (hexane and methanol) was added separately to a $500 \mathrm{~mL}$ round bottom flask. The extraction was done continuously 6 hours at 68 ${ }^{\circ} \mathrm{C}$ for hexane solvent and $64{ }^{\circ} \mathrm{C}$ for methanol solvent. The obtained liquid extracts were concentrated using a rotary evaporator (IKA RV 10 digital). The percentage yield (w/w) of the crude extracts of both plants was calculated and stored in the refrigerator at $5{ }^{\circ} \mathrm{C}$ until used for further experiment.

\section{Phytochemical screening}

Phytochemical screening is the method of finding the main class of chemical compounds present in the plant extracts. The freshly prepared crude extracts were subjected to phytochemical screening using standard procedures (Harborne, 1998). The various phytochemicals present in the extracts were identified by the color reaction with different reagents.

\section{Biological assay}

The brine shrimp lethality assay of each extract was performed to evaluate cytotoxicity by following the standard protocol (Meyer et al. 1982). The method determines the $\mathrm{LC}_{50}$ values (Lethal concentration for $50 \%$ mortality) for the crude extracts. Extract of $\mathrm{LC}_{50}$ value less than $1000 \mathrm{ppm}$ is considered as potentially cytotoxic and pharmacologically active (Montanher et al. 2002).

The artificial seawater was prepared in a small tank to hatch the shrimps. The shrimp eggs were added to the tank containing seawater. A lamp ( 60 watts) was placed above the open side of the tank by adjusting the temperature at $30{ }^{\circ} \mathrm{C}$. After 48 hours, the shrimps mature as nauplii (Artemia salina) and are ready for the assay. Stock solutions were prepared by dissolving $25 \mathrm{mg}$ of each extract separately in DMSO in two separate test tubes. The solution thus prepared was used as a stock solution. From each 
stock solution, solutions of $250 \mu \mathrm{g} / \mathrm{mL}, 125 \mu \mathrm{g} / \mathrm{mL}, 62.5 \mu \mathrm{g} / \mathrm{mL}, 31.25 \mu \mathrm{g} / \mathrm{mL}, 15.625 \mu \mathrm{g} / \mathrm{mL}$ and $7.81 \mu \mathrm{g} / \mathrm{mL}$ were prepared by serial dilution method. $2.5 \mathrm{~mL}$ of each concentration was transferred into test tubes, three for each concentration. Similarly, $2.5 \mathrm{~mL}$ of DMSO was taken in three test tubes as a blank. Labeling of test tubes was done and then they were kept for 24 hours to evaporate the solvent (DMSO). After complete evaporation of the solvent, ten matured shrimps in $5 \mathrm{~mL}$ artificial seawater were transferred to all test tubes containing samples. Similarly, three controlled vials were taken and ten matured nauplii were introduced in each vial. After 24 hours of illumination under a table lamp (60 watts), the numbers of survivors were counted with the help of disposable pipettes. The $\mathrm{LC}_{50}$ value (lethal concentration for $50 \%$ mortality) was determined using probit regression (Finney, 1971).

\section{Antioxidant activity test}

The free radical scavenging activity or antioxidant activity of each extract was measured by using DPPH (1,1-diphenyl-2picryl hydrazyl) radical scavenging assay by following the standard protocol with some modifications (Hossain et al. 2011), (Sharma et al. 2015). Different concentrations $(10,30,50,70,90 \& 110 \mu \mathrm{g} / \mathrm{mL})$ of extracts and ascorbic acid (positive control) were prepared. From each solution, $1 \mathrm{~mL}$ of each solution was taken in different Eppendorf tubes. $1 \mathrm{~mL}$ of the $0.2 \mathrm{mM} \mathrm{DPPH}$ solution was added on each tube containing $1 \mathrm{~mL}$ solution. The tubes were shaken and allowed to stand at $30{ }^{\circ} \mathrm{C}$ for half an hour. The absorbance of each solution was taken on a UV-Visible spectrophotometer (UV professional double beam, Shimadzu made) at $517 \mathrm{~nm}$. Lower the absorbance of the reaction mixture indicates higher free radical scavenging activity. The experiment for each extract was performed in triplicate and the percentage radical scavenging activity was calculated using the following equation (Subba \& Basnet, 2014):

$\%$ radical scavenging activity $=\left(\mathrm{Abs}_{\text {control }}-\mathrm{Abs}_{\text {sample }_{\text {e }}} / \mathrm{Abs}_{\text {control }_{x}}\right)_{x} 100 \%$

The sample which shows a higher percentage radical scavenging activity can act as strong antioxidants (Sharma et al. 2015). The graph of concentration of extract versus the percentage of free radical scavenging activity was plotted. Based on this graph, the $\mathrm{IC}_{50}$ value of each extract was calculated. The $\mathrm{IC}_{50}$ value is the inhibitory concentration of the sample required to scavenge $50 \%$ of the free radicals. The concentration corresponds to inhibition percentage 50 on the plot is $\mathrm{IC}_{50}$. $\mathrm{The} \mathrm{IC}_{50}$ values of the samples were compared and the value closest to that of ascorbic acid is considered to have the best antioxidant property (Khalaf et al. 2008).

\section{Results and Discussion}

\section{Extractive values of different extracts}

The plant material (each $50 \mathrm{~g}$ ) was successively extracted with hexane and methanol. The highest amount of extract was obtained with methanol. The results of the yield of the different extracts are shown in Table 1.

Table 1. Percentage yield of different extracts

\begin{tabular}{ccc}
\hline & \multicolumn{2}{c}{$\begin{array}{c}\text { Percentage yield of different } \\
\text { extracts }\end{array}$} \\
Sample taken & Hexane & Methanol \\
\hline Aerial parts of $A$. sessilis & 4.0 & 6.5 \\
Leaves of $M$. oleifera & 5.5 & 7.0
\end{tabular}

\section{Phytochemical screening}

The phytochemical screening of methanol and hexane extracts of M. oleifera and $A$. sessilis (Table 2) showed the presence of different phytoconstituents. Alkaloids, flavonoids, carbohydrates, terpenoids, polyphenols, glycosides, and coumarins were present in methanol extract of both plants. Saponin was present in all extracts while volatile oils, quinines, and phytosterols were absent in all extracts. The result showed that the more polar methanol extract posses more phytoconstituents than non-polar hexane extracts. The antioxidant and other biological properties of the plant are related to the presence of these phytochemicals in the extracts (Rice-Evans et al. 1996), (Kota et al. 2017), (Gupta et al. 2012). 
Table 2: Results of phytochemical screening of different extracts

\begin{tabular}{|c|c|c|c|c|}
\hline \multirow[b]{2}{*}{ Phytochemicals } & \multicolumn{2}{|c|}{ Alternanthera sessilis } & \multicolumn{2}{|l|}{ Moringa oleifera } \\
\hline & Methanol extract & Hexane extract & Methanol extract & Hexane Extract \\
\hline Tannins & - & - & +++ & - \\
\hline Alkaloids & & & & \\
\hline a) Dragendroff's test & & & ++ & - \\
\hline b) Mayer's test & + & - & + & - \\
\hline Flavonoids & ++ & + & ++ & - \\
\hline Proteins & - & - & + & - \\
\hline Carbohydrates & & & & \\
\hline a) Fehling's test & ++ & - & + & - \\
\hline b) Molisch's test & + & - & ++ & - \\
\hline Coumarins & + & + & ++ & - \\
\hline Quinones & - & - & - & - \\
\hline Phytosterols & - & - & - & - \\
\hline Saponins & ++ & + & +++ & + \\
\hline Terpenoids & + & + & + & - \\
\hline Fats and fixed oils & - & - & - & ++ \\
\hline Volatile oils & - & - & - & - \\
\hline Polyphenols & ++ & - & + & - \\
\hline Glycosides & + & - & + & - \\
\hline
\end{tabular}

Key: $+=$ Present $-=$ Absent

\section{Biological assay}

Brine shrimp lethality activity of the plant extracts was calculated by using probit regression and shown in table 3 . Crude extracts resulting in $\mathrm{LC}_{50}$ values of less than $1000 \mu \mathrm{g} / \mathrm{ml}$ were considered significantly active and had the potential for further investigation. The methanol extract of both plants $A$. sessilis and $M$. oleifera were found to be cytotoxic against brine shrimps as shown by their $\mathrm{LC}_{50}$ values $255.40 \mu \mathrm{g} / \mathrm{mL}$ and $380.50 \mu \mathrm{g} / \mathrm{mL}$ respectively. The hexane extract of $A$. sessilis showed the $\mathrm{LC}_{50}$ value of $925.68 \mu \mathrm{g} / \mathrm{mL}$ and $M$. oleifera showed $>1000$. The results revealed that the active constituents were mainly distributed in the methanol extract of both plants.

Table 3: Brine shrimp bioassay and antioxidant activity results of plant extracts and ascorbic acid

\begin{tabular}{|l|l|l|}
\hline Sample taken & Extract & $\mathrm{LC}_{50}$ value $(\mu \mathrm{g} / \mathrm{mL})$ \\
\hline \multirow{2}{*}{ Alternanthera sessilis } & Methanol & 255.40 \\
\cline { 2 - 3 } & Hexane & 925.68 \\
\hline \multirow{2}{*}{ Moringa oliefera } & Methanol & 380.50 \\
\cline { 2 - 3 } & Hexane & $>1000$ \\
\hline
\end{tabular}

\section{Antioxidant activity test}

The radical scavenging activity of different extracts and ascorbic acid (taken as standard) was evaluated using the DPPH assay. Table 4 represents the absorbance values and \% radical scavenging activity of plant extracts and the standard taken at different concentrations. $\mathrm{IC}_{50}$ value of ascorbic acid (Figure 2) and each extract was calculated from the plot between concentration and $\%$ radical scavenging activity (Figure 1). Methanol extracts of $M$. oleifera exhibited a higher potential of radical scavenging 
activity, with an $\mathrm{IC}_{50}$ value of $65.77 \mu \mathrm{g} / \mathrm{mL}$ compared to its hexane extract $\left(\mathrm{IC}_{50}\right.$ value $\left.88.90 \mu \mathrm{g} / \mathrm{mL}\right)$. Similarly, methanol extract of $A$. sessilis showed high antioxidant activity $\left(\mathrm{IC}_{50}\right.$ value $\left.71.10 \mu \mathrm{g} / \mathrm{mL}\right)$ than its hexane extract $\left(\mathrm{IC}_{50}\right.$ value $\left.92.54 \mu \mathrm{g} / \mathrm{mL}\right)$. It was found that methanol extract of both plants possesses high antioxidant activity as their $\mathrm{IC}_{50}$ values were found to be close to the $\mathrm{IC}_{50}$ value of standard ascorbic acid taken $(39.53 \mu \mathrm{g} / \mathrm{mL})$.

Table 4: Absorbance values and \% of radical scavenging at different concentrations of samples

\begin{tabular}{|c|c|c|c|c|c|c|c|c|c|c|}
\hline \multirow{3}{*}{$\begin{array}{c}\text { Concentration } \\
\qquad(\mu \mathrm{g} / \mathrm{mL})\end{array}$} & \multicolumn{5}{|c|}{ Absorbance values } & \multicolumn{5}{|c|}{$\%$ Free radical scavenging } \\
\hline & \multicolumn{2}{|c|}{ A. sessilis } & \multicolumn{2}{|c|}{ M. oleifera } & \multirow{2}{*}{$\begin{array}{l}\text { Ascorbic } \\
\text { acid }\end{array}$} & \multicolumn{2}{|c|}{ A. sessilis } & \multicolumn{2}{|c|}{ M. oleifera } & \multirow{2}{*}{$\begin{array}{c}\text { Ascorbic } \\
\text { acid }\end{array}$} \\
\hline & $\mathrm{ME}$ & $\mathrm{HE}$ & $\mathrm{ME}$ & $\mathrm{HE}$ & & $\mathrm{ME}$ & $\mathrm{HE}$ & $\mathrm{ME}$ & $\mathrm{HE}$ & \\
\hline 0 & 0 & 0 & 0 & 0 & 0 & 0 & 0 & 0 & 0 & 0 \\
\hline 10 & 0.486 & 0.623 & 0.491 & 0.615 & 0.366 & 30.6 & 11 & 29.9 & 12.1 & 47.7 \\
\hline 30 & 0.404 & 0.532 & 0.441 & 0.531 & 0.287 & 42.3 & 24 & 37 & 24.2 & 59.0 \\
\hline 50 & 0.347 & 0.488 & 0.375 & 0.466 & 0.237 & 50.5 & 30.3 & 46.3 & 33.5 & 66.1 \\
\hline 70 & 0.326 & 0.417 & 0.299 & 0.389 & 0.216 & 53.4 & 40.4 & 57.2 & 44.5 & 69.2 \\
\hline 90 & 0.314 & 0.332 & 0.263 & 0.335 & 0.179 & 55.1 & 52.6 & 62.5 & 52.2 & 74.5 \\
\hline 110 & 0.287 & 0.329 & 0.241 & 0.319 & 0.154 & 59.0 & 53.0 & 65.6 & 54.5 & 78.0 \\
\hline \multicolumn{6}{|c|}{$\mathrm{IC}_{50}$ value $(\mu \mathrm{g} / \mathrm{mL})$} & 71.10 & 92.54 & 65.77 & 88.9 & 39.53 \\
\hline
\end{tabular}

Absorbance of control $(1 \mathrm{~mL} \mathrm{MeOH}+0.5 \mathrm{~mL} \mathrm{DPPH})=0.7$

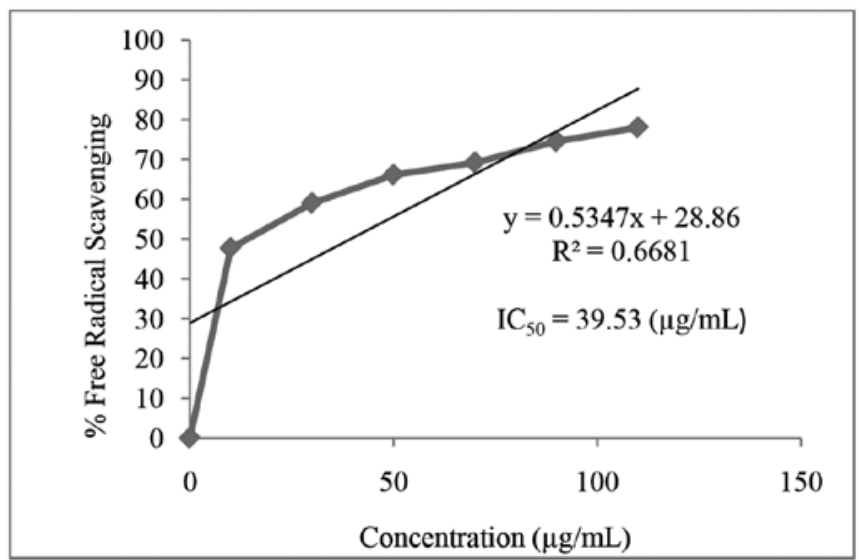

Fig 1: Percentage radical scavenging activity of ascorbic acid at different concentrations

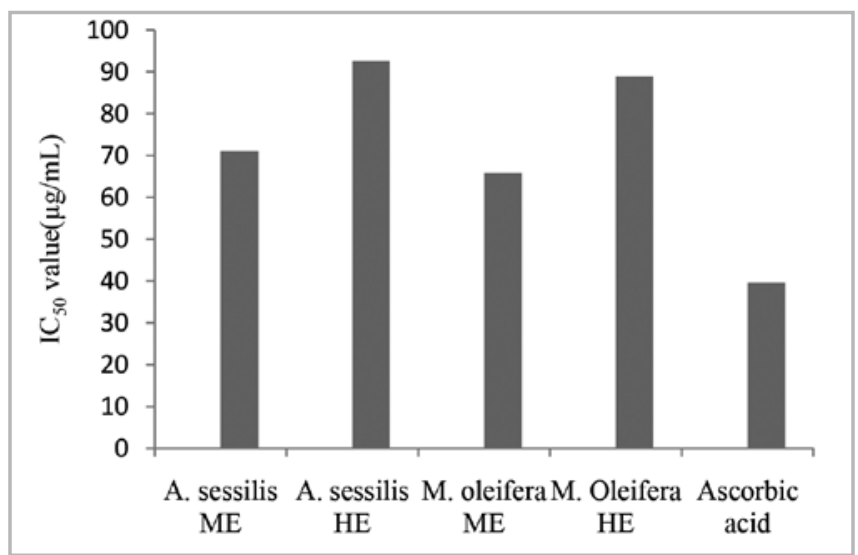

(ME: Methanol extract, HE: Hexane extract)

Fig 2: $I C_{50}$ values of different extracts and ascorbic acid 
Polyphenols and flavonoids found in methanol extracts of A. sessilis and M. oleifera (Table 2) are recognized as potent sources of antioxidants. Several previous studies also reported that the methanol extract of M. oleifera leaves contained polyphenols and had DPPH radical scavenging activity (Kumbhare, et al. 2012), (Shahriar, 2012), (Suphachai, 2014). The results reflect that A. sessilis and M. Oleifera can act as a very good option in the field of medicine based on the antioxidant property of natural products chemistry.

\section{Conclusions}

Phytochemical screening of methanol and hexane extracts of M. oleifera and A. sessilis chiefly showed the presence of alkaloids, flavonoids, carbohydrates, terpenoids, polyphenols, glycosides, coumarins, and saponins. More phytoconstituents were present in methanol extracts than that of in hexane extracts. Brine shrimp bioassay showed that all extracts except hexane extract of M. oleifera were cytotoxic against brine shrimp nauplii. Analysis of DPPH free radical scavenging of the extracts showed that both plants are highly potent in terms of antioxidant activity and the extent of antioxidant activity is following the presence of chief phytoconstituents like flavonoids and polyphenols present in the plant. Further research is recommended to explore these plants as dietary supplements as a source of antioxidants.

\section{Acknowledgements}

We would like to thank the Department of Chemistry, Amrit Campus, Tribhuvan University, Kathmandu and Department of Forest and Soil Conservation, Babarmahal, Kathmandu for providing the laboratory facility.

\section{References}

Anwar, F., Latif, S., Ashraf, M. and Gilani, A.H. 2006. Moringa oleifera: a food plant with multiple medicinal uses. Phytotherapy Research. 21(1): 17-25.

Arora, D.S. and Onsare, J.G. 2014. In vitro antimicrobial potential, biosafety and bioactive phytoconstituents of Moringa oleifera stem bark. World Journal of Pharmaceutical Research. 3(2): 2772-2788.

Balakrishnan, B., Ayyavoo, J., Sadayan, P. and Abimannan, A. 2013. Evaluation of antioxidant activity of Clitoria ternatea and Alternanthera sessilis plant extracts using model system for yeast cells. African Journal of Basic \& Applied Sciences. 5(3): 134-138. DOI: 10.5829/idosi.ajbas.2013.5.3.1135.

Borah, A., Yadav, R.N.S. and Unni, B.G. 2011. In vitro antioxidant and free radical scavenging activity of Alternanthera sessilis. International Journal of Pharmaceutical Sciences and research. 2(6): 1502-1506.

Bukar, A., Uba, A. and Oyeyi, T. 2010. Antimicrobial profile of Moringa oleifera extracts against some food - borne microorganisms. Bayero Journal of Pure and Applied Sciences. 3(1): 43-48. https://doi.org/10.4314/bajopas.v3i1.58706.

Dhanani, T., Shah, S., Gajbhiye, N.A. and Kumar, S. 2017. Effect of extraction methods on yield, phytochemical constituents and antioxidant activity of Withinia somnifera. Arabian Journal of Chemistry. 10(1): 1193-1199. doi.org/10.1016/j. arabjc.2013.02.015.

Finney, D. 1971. Probit analysis, third edition. Cambridge University Press, Cambridge, UK.

Gupta, R., Mathur, M., Bajaj, V.K., Katariya, P., Yadav, S., Kamal, R. and Gupta, S. 2012. Evaluation of antidiabetic and antioxidant activity of Moringa oleifera in experimental diabetes. 4: 164-171.

Harborne, A.J. 1998. Phytochemical methods: A guide to modern techniques of plant analysis. Springer Science \& Business Media, UK.

Hossain, M.A., Shah, M.D., Gnanaraj, C. and Iqbal, M. 2011. In vitro total phenolics, flavonoids contents and antioxidant activity of essential oil, various organic extracts from the leaves of tropical medicinal plant Tetrastigma from Sabah. Asian Pacific Journal of Tropical Medicine. 4(9): 717-721. https://doi.org/10.1016/S1995-7645(11)60180-6. 
Hossain, A.I., Faisal, M., Rahman, S., Jahan, R. and Rahmatullah, M. 2014. A preliminary evaluation of antihyperglycemic and analgesic activity of Alternanthera sessilis aerial parts. BMC Complementary and Alternative Medicine. 14(1): 169-173.

Jalalpure, S.S., Agrawal, N., Patil, M.B., Chimkode, R. and Tripathi, A. 2008. Antimicrobial and wound healing activities of leaves of Alternanthera sessilis Linn. International Journal of Green Pharmacy. 2(3): 156-163.

Khalaf, N.A., Shakya, A.K., Al-Othman, A., El-Agbar, Z. and Farah, H. 2008. Antioxidant activity of some common plants. Turkish Journal of Biology. 32(1): 51-55.

Kota, S., Govada, V.R., Anantha, R.K. and Verma, M.K. 2017. An Investigation into phytochemical constituents, antioxidant, antibacterial and anti-cataract activity of Alternanthera sessilis, a predominant wild leafy vegetable of South India. Biocatalysis and Agricultural Biotechnology. 10: 197-203.

Kumbhare, M., Guleha, V. and Sivakumar, T. 2012. Estimation of total phenolic content, cytotoxicity and in-vitro antioxidant activity of stem bark of Moringa oleifera. Asian Pacific Journal of Tropical Disease. 2(2): 144-150. https://doi.org/10.1016/ S2222-1808(12)60033-4.

Meyer, B.N., Ferrigni, N.R., Putnam, J.E., Jacobsen, L.B., Nichols, D.E. and McLaughlin, J.L. 1982. Brine shrimp: A convenient general bioassay for active plant constituents. Planta Medica. 45(5): 31-34. https://doi.org/10.1055/s-2007-971236.

Montanher, A.B.P., Pizzolatti, M.G. and Brighente, I.M.C. 2002. An application of the brine shrimp bioassay for general screening of brazilian medicinal plants. ActaFarm. Bonaerense. 21(3): 175-8.

Murugan, S. M., Reshma, A., Deepika, R., Balamurugan, S. and Sathishkumar, R. 2013. Antioxidant capacities of Amaranthus tristis and Alternanthera sessilis: A comparative study. Journal of Medicinal Plants Research. 7(30): 2230-2235. DOI: 10.5897/JMPR2013.2567.

Moyo, B., Masika, P.J., Hugo, A. and Muchenje, V. 2011. Nutritional characterization of Moringa (Moringa oleifera Lam.) leaves. African Journal of Biotechnology. 10(60): 925-933.

Nayak, P., Nayak, S., Kar, D. and Das, P. 2010. Pharmacological evaluation of ethanolic extracts of the plant Alternanthera sessilis against temperature regulation. Journal of Pharmacy Research. 3(6): 1381-1383.

Rahman, A. and Gulshana, M. 2014. Taxonomy and medicinal uses on amaranthaceae family of rajshahi, Bangladesh. Applied Ecology and Environmental Sciences. 2(2): 54-59.

Rice-Evans, C.A., Miller, N.J. and Paganga, G. 1996. Structure-antioxidant activity relationships of flavonoids and phenolic acids. Free Radical Biology and Medicine. 20(7): 933-956.

Shahriar, M. 2012. Preliminary phytochemical screening, in-vitro antioxidant and cytotoxic activity of five different extracts of Moringa oleifera Leaf. Journal of Applied Pharmaceutical Science. 2(5): 65-68. https://doi.org/10.7324/JAPS.2012.2510.

Sharma, K.R., Kalauni, S.K. and Awale, S. 2015. Antioxidant, phytotoxic and antimicrobial activities of methanolic extract of Bauhinia variegata Barks. Journal of Institute of Science and Technology. 20(2): 37-41. https://doi.org/10.3126/jist. v20i2.13946.

Siew, Y.Y., Zareisedehizadeh, S., Seetoh, W.G., Neo, S.Y., Tan, C.H. and Koh, H.L. 2014. Ethnobotanical survey of usage of fresh medicinal plants in Singapore. Journal of Ethnopharmacology. 155(3): 1450-1466. https://doi.org/10.1016/j. jep.2014.07.024.

Subba, B. and Basnet, P. 2014. Antimicrobial and antioxidant activity of some indigenous plants of Nepal. Journal of Pharmacognosy and Phytochemistry. 3(1): 62-67.

Suphachai, C. 2014. Antioxidant and anticancer activities of Moringa oleifera leaves. Journal of Medicinal Plants Research. 8(7):318-325. https://doi.org/10.5897/JMPR2013.5353.

Walter, T.M., Merish, S. and Tamizhamuthu, M. 2014. Review of Alternanthera Sessilis with Reference to Traditional Siddha Medicine. International Journal of Pharmacognosy and Phytochemical Research. 6(2): 249-254. 